\title{
Arguing as a Virtuous Arguer Would Argue
}

\author{
José ÁNGEL GASCóN
}

Universidad Nacional de Educación a Distancia

Paseo Senda del Rey, 7, 28040,

Madrid, Spain

jagascon@bec.uned.es

\begin{abstract}
A virtue approach to argumentation would focus on the arguers' character rather than on her arguments. Therefore, it must be explained how good arguments relate to virtuous arguers. This article focuses on this issue. It is argued that, besides the usual logical, dialectical, and rhetorical standards, a virtuously produced good argument must meet two additional requirements: the arguer must be in a specific state of mind, and the argument must be broadly conceived of as an argumentative intervention and thus excel from every perspective.
\end{abstract}

\begin{abstract}
Resumé: Une approche à l'argumentation fondée sur des vertus devrait être axée sur le caractère des raisonneurs plutôt que sur leurs arguments. Par conséquent, il doit être expliqué comment de bons arguments se rapportent aux raisonneurs vertueux. Cet article se concentre sur cette question. On fait valoir que, outre les normes logiques, dialectiques, et rhétoriques typiques, un bon argument produit vertueusement doit répondre à deux exigences supplémentaires: le raisonneur doit être dans un état d'esprit spécifique, et l'argument doit être largement conçu comme une intervention argumentative et donc doit exceller sur tous les plans.
\end{abstract}

Keywords: arguer, argument, character, ethics, skill, virtue

\section{Introduction}

A virtue approach of argumentation, which has been proposed by Daniel Cohen (2013a, 2013b) and Andrew Aberdein (2010, 2014), could be an excellent framework for addressing issues like education in critical thinking, but it would also imply a considerably different analysis from those we are familiar with in informal logic, pragma-dialectics and rhetoric. One of the main theoretical concerns may be the relationship between the goodness of the argument and the virtue of the arguer. In actbased approaches, the virtue or goodness of the arguer could be explained in terms of whether her actions conform to certain standards of goodness. A good arguer, in informal logic terms, can be defined as an arguer that consistently produces good arguments according to the standards of informal logic. 
Alternatively, a bad arguer can be defined in informal logic as an arguer that consistently puts forward poor arguments.

The steps from good arguments to good arguers and from bad arguments to bad arguers are deemed relatively unproblematic. It is natural, almost immediate, to conceive of the goodness or badness of arguers as a function of the quality of their products and actions. A single bad argument does not make a bad arguer, of course, but the habitual production of bad arguments indubitably does.

In a virtue theory of argumentation, the relationship between the quality of the arguers and the quality of the arguments would be the reverse. As Aberdein (2010, p. 170) notes, a virtue approach to argumentation should take the virtues or vices of the arguer as primitive, and explain the qualities of the arguments in terms of the qualities of the arguer. However, this implies a step that does not seem so evident. In particular, it is commonly assumed that arguments must be assessed on their own merits, and that basing the assessment of an argument on the arguer's traits constitutes an ad hominem fallacy. Aberdein (2014) deals with this problem and provides several examples of arguments in which the arguer's traits are relevant for the evaluation. However, we should remember that in act-based theories of argument the quality of the arguer follows from the quality of the arguments she habitually presents, not from a single argument. The reverse relationship, I believe, holds: the quality of the arguments an arguer habitually puts forward follows from her virtues or vices. This is so because one of the conditions for being virtuous is performing well on a reliable basis. As the virtue epistemologist Linda Zagzebski (1996, p. 134) puts it:

Virtue possession requires reliable success in attaining the ends of the motivational component of the virtue. This means that the agent must be reasonably successful in the skills and cognitive activities associated with the application of the virtue in her circumstances.

Note, however, that this does not provide us with an evaluation of any specific argument in isolation. If a person is a virtuous arguer, it does not follow that a particular argument that she puts forward on one occasion is good. It is generally believed that a virtuous individual has a reliable disposition to produce good products, not an infallible one.

What, then, is the precise relationship between a virtuous arguer and a good argument? What I have said so far may sound reasonable - at least I hope so-but it is not very clarifying. Does such relationship consist merely in the fact that the 
majority of arguments that the virtuous arguer puts forward are good? Could it all come down to the proportion of good arguments she produces? Of course, virtue argumentation theory could always stipulate that a good argument is one that a virtuous arguer would put forward, thus strengthening the link between arguers and arguments, but this still strikes me as of little explanatory value.

As is well known, arguments can be regarded either as products or as processes - as "something one person makes" or as "something two or more persons have" (O'Keefe, 1977, p. 121). When Ralph Johnson developed his own theory of argument, he wrote (2000, p. 154):

To develop an adequate understanding of argument, we must situate it within the practice of argumentation, which includes as components (a) the process of arguing, (b) the agents engaged in the practice (the arguer and the Other), and (c) the argument itself as a product.

A virtue theory of argumentation must focus on the agents and attempt to explain how they relate both to the process of arguing and to its products. In this article, I will explore the relationship between informal logic, as the main approach to the study of arguments as products, and (my own view of) a virtue theory of argumentation. Much can-and should-be said about the relationship between dialectical approaches, such as pragmadialectics, and a virtue theory of argumentation, and this would shed light on the relationship between the argumentative virtues and argumentation as a process. However, I believe such a study deserves an article on its own. Here I will focus on how a virtue approach to argumentation could deal with arguments as products.

The appraisal of arguments has been, in fact, the first matter of concern for both proponents and critics of a virtue approach to argumentation. Bowell and Kingsbury (2013) have warned against using traits of the arguer as the basis for argument appraisal, while Aberdein $(2010,2014)$ has argued that it can be done and can actually be a fruitful methodology. Fabio Paglieri (2015) offers an insightful analysis of this discussion, and claims that one of the benefits of virtue argumentation theory could precisely be the adoption of a broader conception of argument than that of informal logic. This is one of the paths that I will pursue in this article.

Cohen, on the other hand, has argued for a strong link between the traits of the arguer and the quality of the argument. He claims (2013b, pp. 482-483): 
Isn't an accidentally produced good argument just as good as a virtuously produced one? [...] the answer is still "No" and for the same reasons that accidentally true beliefs do not count as knowledge. Otherwise, arguers would not have the requisite "ownership" of their arguments, a relation that grounds responsibility and the assignment of blame and credit.

This is an interesting idea. Indeed, it seems that a virtue theory of argumentation, with its focus on arguers, could emphasise the responsibility that arguers have for the arguments they put forward in order to assign blame and credit. Responsibility and assignment of blame and credit are key features of virtue approaches to ethics as well as of virtue responsibilist approaches to epistemology. But, as I intend to show in the next section, such "ownership" is not so easily explained in argumentation theory as it is in epistemology. The traditional approach to arguments does not allow for the introduction of the agent, as opposed to the traditional approach to beliefs. My proposal, though, is that virtue argumentation theory should adopt Cohen's claim, and then work out a conception of argument that give sense to that idea. The reason is that taking the agent into account and holding her accountable for her products are, I believe, among the most valuable features of virtue theories.

In the previous quote, Cohen (a) acknowledges that a good argument can be accidentally produced, presumably by a nonvirtuous arguer, but at the same time (b) holds that a virtuously produced argument is something more than simply a good argument. I believe it is safe to assume that a virtuously produced argument means an argument produced by a virtuous arguer, and that an accidentally produced good argument is an (intentionally produced) argument that is luckily good. ${ }^{1}$ Thus, it seems that a non-virtuous arguer can in fact put forward a good argument, but that being a virtuous arguer consists in producing arguments that are somehow better.

This distinction between good arguments and virtuously produced arguments will be the key to my explanation of the relationship between informal logic and virtue argumentation theory. But first, in the following section, I will discuss some relevant differences between argumentation theory and epistemology, which might help explain why virtue argumentation theory faces some important challenges that virtue epistemology does not.

\footnotetext{
${ }^{1}$ Andrew Aberdein drew my attention to this potential ambiguity.
} 


\section{The good and the virtuous}

What makes a good argument? According to the traditional account of informal logic, there are three requirements that the premises of an argument must satisfy for that argument to be considered to be good: acceptability, relevance, and sufficiency or good grounds. Instead of the goodness of the argument, we should talk more precisely about cogency. Trudy Govier (2010, p. 87) explains the three criteria for cogency: acceptability means that "it is reasonable for those to whom the argument is addressed to believe these premises"; relevance means that the premises are relevant to the conclusion, state evidence or offer reasons that support the conclusion; and good grounds-or sufficiency - means that the premises, considered together, give sufficient support to the conclusion.

In order to ensure that we take a sufficiently strong conception of the cogent argument, let us consider an additional requirement. Johnson (2000, pp. 206-208) argues that the very presence of an argument implies that the issue is at least potentially controversial: there might be different opinions, arguments for and against each view, well-known objections, and so forth. A cogent argument must take into account this dialectical dimension, hence the necessity of a dialectical criterion: the dialectical tier. The assessment of the dialectical tier should include, among other possible issues:

- Anticipating standard objections to a premise of the argument.

- Anticipating standard objections to the conclusion of the argument.

- Addressing alternative positions.

- Anticipating the consequences and implications of one's position.

We have then three criteria-acceptability, relevance, and sufficiency or good grounds-corresponding to what Johnson (2000, p. 190) calls the illative core, as well as the dialectical tier. A brief reflection on these standards might help our inquiry into the relationship between arguments and arguers.

Firstly, note that the criteria of relevance and sufficiency are properties of the argument; they assess an internal relationship of the argument, that between its premises and its conclusion. Secondly, the criterion of acceptability concerns the relationship between the premises and the audience; it is intended to assess the extent to which the premises are consistent with the audience's beliefs or the extent to which the 
audience is willing to accept the premises. And, finally, the dialectical tier involves the assessment of the relationship between the argument and other well-known or expected arguments-how well the argument fares in the presence of contrary arguments.

Ralph Johnson (2000, p. 334) explicitly analyses the relationships that each criterion involves. He represents the argument as "an intellectual force determined by three vectors." The first vector, corresponding to the criteria of relevance and sufficiency, "goes from the premises to conclusion." The second vector, representing the criterion of acceptability, "goes from the premises to the audience." Whereas it is still under discussion whether the first criterion should be acceptability or truth, Johnson (2000, pp. 195-198) adopts both criteria. Hence, the vector of truth "is determined by the direction that goes from the premises of the argument to the world." Finally, Johnson holds that the criteria for the dialectical tier "can be accounted for in the vector from the premises to the audience" (p. 335). This differs from my proposal that the dialectical tier be understood as the relationship between the present argument and other arguments, but that does not affect the point I am interested in making.

Notice that, consistent with the traditional assumption that every argument must be assessed on its own merits, the arguer himself or herself is not taken into consideration by any of those standards. Arguments, therefore, are evaluated without reference to the individuals that put them forward - they could just as well be evaluated as if they were anonymous. It is therefore understandable that some authors are suspicious of the virtue theorists' attempt to incorporate the arguer into the evaluation of the argument - and what is more, to make the arguer's character the basis of such evaluation. Thus, Bowell and Kingsbury (2013) hold that it is never legitimate to adduce traits of the arguer to reject her argument, and that for this reason "virtue argumentation theory does not offer a plausible alternative to a more standard agent-neutral account of good argument" (p. 23). In a similar vein, David Godden (2015) argues that virtue argumentation theory "cannot provide a complete account of argumentative goods and norms" (p. 12) for it has to rely on an "entirely independent, non-aretaic normative conditionnamely, a good reason" (p. 8, his emphasis).

Even though I do not share these authors' concerns, I believe that it would be a mistake to ignore or downplay their criticisms, for they illustrate an important difference between argumentation theory and the other disciplines that have adopted a virtue approach - ethics and epistemology. As will be shown, 
Cohen's contention, cited earlier, that an accidentally good argument is not so good "for the same reasons that accidentally true beliefs do not count as knowledge" is not so evident.

Both ethics and epistemology have traditionally included the subject of action or knowledge in their evaluations. Consider the case of epistemology. The traditional definition of knowledge states three conditions for a given belief $(p)$ to constitute knowledge:

1. The individual believes $p$.

2. The individual is justified in believing $p$.

3. $p$ is true.

Conditions 1 and 2 make explicit reference to the individual; for this reason, one cannot decide whether a certain belief constitutes knowledge without taking into consideration the person who has that belief. Moreover, condition 2 is intended to rule out accidentally true beliefs: for a belief to be knowledge, the individual must have obtained it through a reliable process, or she must have good reasons to believe it, or the like. An accidentally true belief, by its very definition, is not knowledge.

This might be one of the reasons why virtue epistemology has been so successful. There is an obvious relationship between true beliefs constituting knowledge and virtuous agents; beliefs cannot be evaluated without reference to the agent. For this reason, the definition of knowledge that virtue epistemology provides, which takes the agent's traits as the basic concept, seems plausible. One of the definitions that Zagzebski (1996, p. 271) provides, for example, is: "Knowledge is a state of true belief arising out of acts of intellectual virtue." This definition, then, explicitly rules out beliefs that are accidentally true, just as the traditional definition of knowledge does.

The situation is similar in ethics. Although many exceptions could be discussed in this regard, in general most ethical theories include the concept of intention in one way or another ${ }^{2}$, and this concept establishes a link between the action and the agent. In order to decide on the rightness or wrongness of an action, it is therefore necessary to know, among other things, what the agent intended to accomplish. An action cannot be evaluated without taking into account the agent, even if that action has manifestly good or bad consequences. The reason is that, in most accounts, an action that accidentally has good consequences does not count as a right action.

\footnotetext{
${ }^{2}$ Some consequentialist theories, which evaluate the rightness or wrongness of the actions according to the consequences they bring about, speak of intended and foreseen consequences.
} 


\section{Gascón}

Thus, we can see what the crucial difference is between argumentation theory, on the one hand, and ethics and epistemology, on the other. Not only has the arguer been traditionally excluded from the evaluation of arguments, but taking the arguer into account has even been considered in most cases as a fallacious move-ad hominem. It seems, then, that from this point of view an accidentally good argument is just as good as a virtuously produced one.

How can that be so? We can gain some insight by reading Aristotle's arguments, in Nicomachean Ethics (II.4.1105a), for his distinction between virtues and skills:

Again, the case of the skills is anyway not the same as that of the virtues. For the products of the skills have their worth within themselves, so it is enough for them to be turned out with a certain quality. But actions done in accordance with virtues are done in a just or temperate way not merely by having some quality of their own, but rather if the agent acts in a certain state, namely, first, with knowledge, secondly, from rational choice, and rational choice of the actions for their own sake, and, thirdly, from a firm and unshakeable character.

A chair, for example, is doubtless the product of a skill, for as long as the chair is of good quality there is no need to learn about the carpenter's character. Since, as we have seen, from the perspective of informal logic arguments are assessed solely on their own merits, perhaps informal logic is actually a skill rather than a virtue. If that is the case, then a virtue approach to argumentation should adopt a different perspective. Informal logic would doubtless be an important skill for a virtuous arguer to have, but argumentative virtue would not be just informal logic. In order to establish a stronger link between the arguer and the argument, argumentative virtue should involve something more.

I believe that is a promising hypothesis. What, then, could we add so that the quality of the argument bears a stronger relationship to the arguer's traits? I can see two possibilities. In the first place, a straightforward solution would simply be to include the requirement that the arguer have a certain (virtuous) state of mind among the criteria for the evaluation of the argument. That is, an argument would be virtuously produced if it is cogent-if it complies with the standard criteria of informal logic-and if it is produced by a virtuous arguer. When developing a virtue approach to argumentation, perhaps this is the easiest path to take. However, there is another, subtler possibility. Virtue argumentation theory could broaden the 
definition of argument, adopting a richer conception than that of informal logic. In this case, it would be possible to specify more criteria for the evaluation of the argument - in addition to the strictly logical criteria of acceptability, relevance, sufficiency, and the dialectical tier. Those additional criteria could thus be shown to depend more closely on the arguer's traits. ${ }^{3}$

In the following two sections, I will consider the two possibilities that have been mentioned. Then, in section 5, I will propose a solution based on both possibilities and I will explain some important consequences it has for a virtue approach to the argument.

\section{The requirement of the state of mind}

If informal logic is actually a skill, something more is needed for an arguer to be virtuous. After all, as Daniel Cohen (2013a, p. 16) says: "Not every skill is a virtue; skillful arguers can be quite vicious!" What else do we need? A possibility is the requirement, which some virtue theories highlight, that the individual must be in a particular state of mind. This is in fact what Aristotle points out in the passage cited above: virtuous actions are those that the agent performs (a) with knowledge, (b) from rational choice, and (c) from a firm and unshakeable character. An accidentally good action, on this account, cannot be a virtuous action, it is also necessary that the agent be aware of what she is doing, choose to do so, and have a reliable disposition to act that way in similar circumstances. In other words, not only the action itself, but also what is going on in the agent's head is crucial for it to be a virtuous action.

Modern virtue ethics theorists emphasise this requirement as well. A distinction is commonly made between actions that are right and virtuous actions - or acts of virtue. Robert Adams (2006, p. 9), for example, explains that virtue cannot be defined merely in terms of right actions_-as, say, a reliable disposition to perform right actions - for such a definition offers us "an impoverished conception of virtue". Moreover, Julia Annas (2011, p. 43), from the point of view of her own theory of

\footnotetext{
${ }^{3}$ There is, of course, a third possibility, which is to define the criteria of informal logic in virtuistic terms. Paglieri (pp. 79-80) explores the possibility of defining relevance as a virtue. Likewise, both Andrew Aberdein and Hubert Marraud (personal communications) suggested that the dialectical tier could be characterised on the basis of the arguer. Although these are intriguing suggestions, I am not sure whether an agent-based account of those terms would be clearly explanatory-perhaps it would, but I prefer to keep a conservative view until convinced otherwise.
} 
virtue, insists on the uninformative nature of the weak concept 'right':

That is, an action's being the right thing to do merely locates it somewhere on a range from a barely acceptable action to a highly meritorious action, but with no indication where on that range it falls. This is not very informative about an action, especially since an action's being right is also no indication of what kind of action it is: brave, generous, loyal, kind, and so forth.

On this account, it is therefore perfectly possible that someone does the right thing without being virtuous - or even being vicious. As Annas (2011, p. 45) says: "A cruel person can do the right thing, where this is a compassionate action, because she is motivated by sentimentality, for example." In order to do, not only the right thing, but the virtuous thing, then, certain thoughts and feelings need to be present in the agent's mind. Annas (2011, p. 47) concludes:

Only the truly virtuous do the right thing as the virtuous person would do it, exhibiting independent understanding of what should be done in a way that takes into account all relevant features of the situation.

What would that amount to in a virtue theory of argumentation? A possible answer lies very close to the field of argumentation theory: in the critical thinking movement. Authors in the critical thinking movement realised that instruction in the skill of producing good arguments and detecting bad ones is not enough. Richard Paul (1993) distinguished between a weak sense of critical thinking, that is, "as a list or collection of discrete intellectual skills", and a strong sense, "as a mode of mental integration, as a synthesized complex of dispositions, values, and skills necessary to becoming a fairminded, rational person" (p. 257). Paul claimed that "critical thinking, in its most defensible sense, is not simply a matter of cognitive skills" ( $p$. 258), and he advocated the fostering of virtues like "intellectual (epistemological) humility, courage, integrity, perseverance, empathy, and fairmindedness" (p. 259). Likewise, Harvey Siegel (1993) defended the view that critical thinking involves both skill and character, arguing that "a worthy product can be achieved by the most uncritical of means" (p. 167). And he claimed that (Ibid.): 
one's status as a critical thinker depends not only on the (propositional) products of one's thought. It depends as well on the process of that thought. It is here that considerations of character arise.

In argumentation theory, Vasco Correia (2012) argues for an approach that includes argumentative virtues, holding that the logical and the dialectical rules are insufficient for the evaluation of everyday arguments. Correia emphasises a number of biases that instruction in the analysis of the structure of the argument cannot purge. He says (p. 225):

Arguments may be correct from a logical and dialectic perspective and nonetheless "unfair" and tendentious. [...] Discussants may scrupulously observe the pragmadialectical code of conduct and nevertheless argue tendentiously.

The requirement of the state of mind, thus, could entail that the argument must be a manifestation of a virtuous character. The arguer must be in a virtuous state of mind, which in this case means that the arguer must produce her arguments out of a virtuous character.

Furthermore, I believe that it is possible to include an additional component in this requirement. Even though virtue theories tend to highlight the naturalness and spontaneity of virtuous acts, ${ }^{4}$ in the case of argumentation theory it is, arguably, sensible to add the condition that, for an argument to be virtuously produced, the arguer must put it forward in a conscious manner. The reason is that the arguer must, among other things, be aware of the argument's strengths and weaknesses, she must know how convincing it is, in which cases it would fail to convince, and why the reasons (or data, premises) are justified. An account of virtue in argumentation could therefore explain why an accidentally produced cogent argument is not as good as a virtuously produced argument.

One can ask, are such considerations really relevant in the evaluation of the argument? After all, as Godden (2015, p. 7) argues, an automated device could in principle be programmed to reliably produce good ("cogent, dialectically adequate, rhetorically persuasive") arguments, even though such device cannot be considered an arguer, let alone a virtuous one. I concede that, in principle, such a device would produce good arguments. However, the automated device cannot answer questions regarding the truth, the relevance or the sufficiency of

\footnotetext{
${ }^{4}$ I thank Jesús Vega for pointing this out to me.
} 
the reasons (or data, premises), it cannot respond to objections, it cannot provide further support for some of its claims, and all this is due to the fact that it does not even understand the argument. ${ }^{5}$ Godden (Ibid.) claims that "we ought to be moved by the arguments 1 produced by such a device,"6 but the idea of an isolated argument by which we should be moved without the necessity of asking any question strikes me as unreasonable. I would not advise anyone to accept any argument unquestioningly, no matter how good. ${ }^{7}$ Granted, the argument would be good, but just in the sense that there would be nothing inherently wrong with it - it would be right. If, on the other hand, the argument is virtuously produced, that is, if at least the arguer understands it and can defend it and respond to objections, then it is reasonable for us to be convinced by it at some point. Arguably, the arguer has an obligation to-at the very least - answer questions regarding her argument. In that sense, the arguer should be held accountable for her arguments, and perhaps this sheds light on Cohen's reference to the "ownership" of arguments.

Annas (2011, p. 51) proposes an analogy between virtue and the skill of speaking a foreign language that might be enlightening in this case:

Suppose we press this: how do we get guidance in action by following directions to become honest and brave? A major theme of this work has already made the answer clear: this is like asking how we get guidance in communicating with Italians by learning Italian (her emphasis).

This is exactly what virtue is about: one does not ask what the honest thing to do is in a particular situation, one asks how to become an honest person, and the honest actions will naturally follow from that. The focus, then, is on education and development of the character, not on rules or principles.

\footnotetext{
${ }^{5}$ If the automated device could do all of that, I would seriously wonder whether it counts as an arguer capable of being virtuous.

${ }^{6}$ See O'Keefe (1977) for the distinction between arguments 1 , the products, and arguments 2 , the processes.

${ }^{7}$ It is quite possible that my disagreement with Godden actually reveals a different conception of argument. He might be thinking of an extended written argument, similar to Johnson's (2000) conception, whereas here I am assuming a conception of argument as a piece of oral communication, which I take as primary. Nevertheless, I insist that, if a device could produce an argumentative text in which it supports potentially contentious reasons and takes into account different points of view, then I am not so sure that it does not count as an actual arguer.
} 
Using Annas' analogy, we can distinguish two kinds of people who might utter a sentence in Italian:

1. Someone who does not speak Italian, and who merely repeats a sentence in Italian she has heard somewhere, or accidentally puts together a few words in the right order.

2. Someone who does speak Italian, who knows precisely what she is saying and who is capable of having a conversation in Italian.

We can see here that in both cases the sentence uttered might be grammatically correct, but the utterance in the first case is not as good as the utterance in the second case. They both uttered a correct sentence in Italian, but only the Italian speaker can be said to speak Italian. Only the Italian speaker can understand the listener's reply and continue the conversation. Likewise, in a sense, accidentally produced good arguments are just as good as virtuously produced arguments - they are both cogent. However, in a different sense, accidentally good arguments are not produced in a conscious and meaningful manner, and hence they do not count as virtuously produced, but as merely right. Some degree of virtue is required if the arguer is to successfully continue the argumentative dialogue by defending her argument, responding to objections, or providing further support for contentious reasons. Thus, the difference does not lie in the product itself-the sentence or the argument-but in the speaker's disposition.

\section{An enriched conception of argument}

The other possibility we could consider is that arguments are something more than a set of premises and a conclusion, plus an inferential step. In that case, the evaluation of the argument would involve something more than the criteria of acceptability, relevance, sufficiency, and dialectical tier. If we take into account properties of the argument that depend more conspicuously on the arguer, then it is legitimate to explain (at least an important part of) the quality of the argument on the basis of traits of the arguer. Indeed, this appears to be Cohen's view when he states (2013b, p. 484): "The common concept of an argument does need some expansion." Michael Gilbert (1995), for example, defends an enriched conception of argument, and concludes (p. 132): 
If we are going to deal with arguments in a more than critical way we need to shift the focus from the argument to the arguer, from the artifacts that happen to be chosen for communicative purposes to the situation in which those artifacts function as a component (his emphasis).

Although Johnson's (2000) theory of argument is focused on arguments as products and on the four criteria explained above, he opens up the "possibility of other normative criteria to be applied to argument," suggesting "such qualities as originality, fertility, ingenuity, and so forth" (p. 336). A broader conception of argument could in fact give us a more comprehensive and down-to-earth picture of what arguments are for ordinary people in everyday situations. The representation of the argument that informal logic assumes, consisting of a set of propositions and an inferential step, is doubtless a useful analytic tool for the study of a specific component of arguments, but it does not give us a complete picture of what is going on in argumentative discussions. As Schreier and Groeben (1996) have shown, people typically evaluate others' interventions in argumentative discussions not just according to logical criteria. Based on empirical research, these authors propose four argumentative conditions that contributions to argumentative discussions must meet "if a rational and cooperative solution is to stay within reach" (1996, p. 124). These conditions are (Schreier, Groeben, \& Christmann, 1995):

- Formal validity: This condition applies to the arguments. The reasons put forward by the arguer must be linked both materially and formally to the claim by means of a warrant.

- Sincerity/truth: This condition applies to the relation between the speaker and the argument. The attitude expressed by the arguer-such as that of believing a proposition-must correspond to her real attitude.

- Justice on the content level: This condition applies to the relation between an argument and the person to whom the argument is addressed. The argument must be just toward the person who receives it.

- Procedural justice: This condition applies to the relation between the arguer and the listener. The argumentative procedure must be conducted in such a way that the opportunities for communication and understanding are not restricted.

Along these lines, arguments could be understood more broadly as a sort of behaviour or communicative act taking place in an argumentative context. For example, Michael Gilbert's (2014) 
theory of coalescent argumentation begins with a proposal to go beyond the logical analysis of arguments and take into consideration other components that are present in every discussion. Gilbert (pp. 58-62) distinguishes four components, or modes, of every argument. The first mode is the logical mode, which involves the elements traditionally studied by informal logic, such as the premises and the inferential step, with which we are all very familiar. The three other modes account for those aspects of the argument that are not logical, but that it is important to consider if we are to make sense of what happens in argumentative interactions. These modes are:

- Emotional: Emotional signals conveyed by words, tone, context, posture and expression.

- Visceral: The setting; all aspects of argument that are physical and circumstantial, such as the location of the participants or the physical actions performed during the discussion (offering a beverage, touching the other's arm, smiling, and the like).

- Kisceral: Values or beliefs that cannot be empirically tested and that are frequently used in the arguments, and that for this reason should be, if not shared, at least understood by the participants.

So rich a conception of the argument would allow for one of the key ideas of virtue approaches: the notion, not of mere rightness, but of excellence. This notion, I believe, takes us closer to the answer to the question that troubles Cohen (2013b, p. 477): "What would make an argument satisfying to the point that the participants could say at the end, 'Now that was a good argument'?"

Admittedly, though, such a definition of argument - the product - as a sort of behaviour could lead us quite far away from the usual conceptions shared by the traditional perspectives in argumentation theory-logic, rhetoric and dialectic. And perhaps so radical a departure from tradition is not necessary. Nevertheless, whether or not the word 'argument' is usedinstead of, say, argumentative intervention - a virtue theory of argumentation should depict people's interventions in argumentative discussions as what they actually are: very rich interactions that involve many factors. Only from such a perspective does it make sense to say that a bad or vicious arguer cannot produce a truly good argument. 


\section{The purpose of a virtue theory of argumentation}

The options sketched in the two previous sections offer the possibility of a virtue approach to the study of the argument by taking into account traits of the arguer. According to the first option, the virtuous arguer must act out of a virtuous character and understand the strengths, weaknesses, and implications of her arguments - and thus the possibility of an accidentally produced good argument is ruled out. According to the second option, we can adopt an enriched conception of argument so that its goodness depends at least partially on traits of the arguer. Which path should we take? It seems to me that both alternatives are compatible and equally important for an understanding of what being a virtuous arguer consists in. Therefore, I suggest that virtue argumentation theory should adopt both views.

Although some authors, such as Aberdein (2014), argue that a virtue approach to argumentation can be a theory of argument appraisal, I am not convinced that it can provide a better, more insightful account of cogency than that of informal logic. For this reason, I have proposed that informal logic be considered as a skill that is crucial for the virtuous arguer to have. Naturally, this implies that virtue argumentation theoryat least as I envisage it - will not be a complete, self-standing theory of argumentation. Some will regard this as a fatal flaw of the theory. But notice that all virtue theories incorporate a component that is best analysed according to act-based criteria: surely the consequences of our actions are relevant in virtue ethics, just as the truth of our beliefs matters in virtue epistemology. On the other hand, some other important aspects of argumentation are arguably best handled by a virtue approach - such as bias and dogmatism. So, in an important sense, no single approach can ever be a complete theory of argumentation.

Viewed from a pedagogical perspective, informal logic can be regarded as the answer to the question 'How can I produce good arguments and decide whether my interlocutor's arguments are good?', whereas virtue argumentation theory could answer a broader question, that is, 'How can I become a good arguer?' Some informal logicians, such as Bowell and Kingsbury (2013, p. 23), conflate both questions. But-and this insight is, in my view, one of the merits of a virtue approach to argumentation-they are not the same, for an arguer can produce good arguments and still be biased, intellectually arrogant, or dogmatic, to name but a few vices. Even though it is true that a virtuous arguer reliably produces cogent arguments, 
mere reliability cannot tell us what being a virtuous arguer consists in. A conception of the virtuous arguer as a mere reliable producer or detector of cogent arguments would be rather poor. More broadly, it is an individual's character, including her insight and sensitivity to good reasons, which characterises a virtuous arguer-and possessing a virtuous character consists in part in having a disposition to produce cogent arguments.

Act-based approaches tend to be analytical and to isolate particular features of the act. The analytic study of arguments is, of course, a very important enterprise, but it should not make us lose sight of the whole picture in all its complexity and richness. 'Do the premises support the conclusion?' is surely an important question, but there are others. For example: Is the arguer biased? Does the arguer show a respect for everybody's motives, goals, and feelings? Has the argument been put forward in order to encourage critical thinking, enquiry, and open exchange of ideas, or is it just aimed at silencing the others? Does the arguer show a disposition to change her mind, or does she exhibit a dogmatic attitude?

I am aware, however, that my proposal that cogency not be defined in agent-based terms has an important - and perhaps undesirable to some-consequence. Godden $(2015$, p. 7$)$ insists on this point:

Seemingly, the probative merits of arguments 1 are independent of the virtue (or even the capacity for virtue) of the arguers advancing them, or generally of the means by which they were produced.

I agree. If we accept that cogency-or, for that matter, validity or soundness - is the best notion when it comes to deciding whether a claim has been adequately supported or not, then by declining to define cogency in agent-based terms, my view of virtue argumentation theory cannot assess the "probative merits" of arguments. The interest in a virtue approach to argumentation, however, lies in the fact that it focuses on other aspects of the argument that the notion of cogency cannot grasp. Of course, arguments have a "probative" component, but that is not all arguments are. Arguments can also be respectful or disrespectful to the listener, they can be timely or disruptive, they can reflect open-mindedness or dogmatism, they can be fair or biased, and so on. Even though virtue argumentation theory might not explain whether a claim has been well supported, this does not mean that such a theory has nothing to say about how to argue reasonably. Quite the contrary. 
Paglieri (2015, p. 73) asks: "why should anyone want to belabour on a fairly rich and complex theory of virtues, and then tie that theory to a definition of quality which is extremely narrow and pays only minimal attention to extra-textual features?" That is exactly the point. The interest of a virtue approach to argumentation lies in the fact that it provides a different perspective from that of informal logic, and this helps us realise that our previous central concerns-such as cogency-were not the only legitimate ones. Virtue theories usually arise out of a dissatisfaction with the perspective and the central concepts of the time. In the case of virtue ethics, G. E. M. Anscombe (1958) famously argued against deontology's focus on the notion of "moral ought." Somewhat less controversially, the virtue epistemologist Christopher Hookway (2003) holds that virtue epistemology can offer a perspective in which the concepts of 'knowledge' and 'justification' are less central, and which focuses instead on other important aspects of epistemic evaluation: "Thus virtue epistemology might fall into place as an account of the evaluations required for wellregulated inquiries and theoretical deliberations" (p. 194). To be clear, though, I am not proposing that we abandon the notion of cogency, but I do believe that we should not narrowly focus on cogency as all that can be said about argument quality.

\section{Conclusion}

I confess that in this article I have focused on an issue that I consider rather tangential and not very enlightening from the point of view of a virtue approach to argumentation: the argument as product. Indeed, in my view, the main advantage of virtue theories is that they offer a novel and interesting perspective on habits and practices - and that is why a virtue approach to argumentation attracted my attention, rather than the prospect of studying isolated arguments, let alone cogency. Nevertheless, recent discussions on virtue argumentation theory (Aberdein, 2014; Bowell \& Kingsbury, 2013; Godden, 2015; Paglieri, 2015) have focused on precisely this point, so an answer seemed necessary.

The main concern of a virtue approach to argumentation, as I envisage it, should be the arguers themselves and their character. That is, the arguer's character should not be regarded as a means to study something else - the argument, say- but as the main interest. This has an obvious pedagogical purpose. The practice of argumentation will be, I believe, naturally improved once character is cultivated. Aberdein $(2014$, p. 78 , note 1$)$ notes 
that "(rhetorical or dialectical) accounts of argument evaluation" are "most congenial to a virtue-theoretic approach." It is not accidental that both accounts focus on the process and practice of argumentation. For a verdict on the goodness of specific arguments, though, virtue argumentation theory might not be the best approach.

Informal logic, as we have seen, can be regarded as a skill, and as such it is not sufficient for differentiating between virtuous and non-virtuous arguers. I have proposed two possible additional requirements for an argument to be virtuously produced: that the arguer be in a specific (virtuous) state of mind, which is consistent with virtue (responsibilist) approaches' focus on the character and disposition of the individual, and that the argument be not only excellent from a logical point of view but also conceived of as a complex and rich communicative act. Since both requirements are compatible and one of the benefits of a virtue approach to argumentation could be its contextually rich and broad perspective, which includes the arguers, I propose that the two possibilities be adopted. In sections 3 and 4, I have tried to show that both ideas are not wholly new, but that they have already been proposed by several authors.

Some might consider that the term 'argument' is inappropriate for the admittedly vast and vague picture that I presented-argument as behaviour that takes place in an argumentative context, following Gilbert. After all, what I depicted is arguably the opposite of the argument as the "the distillate of the practice of argumentation" (Johnson, 2000, p. 168). For this reason, I have proposed instead the term 'argumentative intervention.' Note, however, that this term suggests a dialectic framework and therefore blurs the boundaries between the process and the product. Given what has been said so far, this should come as no surprise. If we expectas I do-virtue argumentation theory to provide a richer and broader picture, it is only understandable that this theory will not handle distillates properly - that was never its purpose. Thus, the distinction between process and product might not be so relevant to virtue argumentation theory after all. ${ }^{8}$

Acknowledgements: A preliminary draft of this paper was presented at the VIII Conference of the Spanish Society for Logic, Methodology and Philosophy of Science. I am grateful for the valuable comments I received from Hubert Marraud,

${ }^{8}$ I thank an anonymous reviewer for this suggestion. 
Paula Olmos and Jesús Alcolea. I must also thank Andrew Aberdein and Jesús Vega, both of whom offered to read a previous version of the paper and sent me very insightful and useful comments. Finally, I thank my colleague Susana Monsó for her comments on the final paper. Whatever mistakes remain can be accounted for only by my own vices. This work was possible thanks to a pre-doctoral scholarship of the UNED.

\section{References}

Aberdein, A. (2010). Virtue in argument. Argumentation, 24(2), $165-179$.

Aberdein, A. (2014). In defence of virtue: The legitimacy of agent-based argument appraisal. Informal Logic, 34(1), 7793.

Adams, R. M. (2006). A theory of virtue: Excellence in being for the good. New York: Oxford University Press.

Annas, J. (2011). Intelligent virtue. New York: Oxford University Press.

Anscombe, G. E. M. (1958). Modern moral philosophy. Philosophy, 33(124), 1-19.

Bowell, T., \& Kingsbury, J. (2013). Virtue and argument: Taking character into account. Informal Logic, 33(1), 22-32.

Cohen, D. H. (2013a). Skepticism and argumentative virtues. Cogency, 5(1), 9-31.

Cohen, D. H. (2013b). Virtue, in context. Informal Logic, 33(4), 471-485.

Correia, V. (2012). The ethics of argumentation. Informal Logic, $32(2), 222-241$.

Gilbert, M. A. (1995). Arguments and arguers. Teaching Philosophy, 18(2), 50.

Gilbert, M. A. (2014). Arguing with people. Peterborough, ON: Broadview Press.

Godden, D. (2015). On the Priority of Agent-Based Argumentative Norms. Topoi. http://doi.org/10.1007/s11245014-9296-x

Govier, T. (2010). A Practical Study of Argument. Belmont: Wadsworth Cengage Learning.

Hookway, C. (2003). How to be a virtue epistemologist. In L. Zagzebski \& M. DePaul (Eds.), Intellectual virtue: Perspectives from ethics and epistemology. New York: Oxford University Press.

Johnson, R. H. (2000). Manifest rationality: A pragmatic theory of argument. Mahwah, NJ: Lawrence Erlbaum Associates. 
O'Keefe, D. J. (1977). Two concepts of argument. The Journal of the American Forensic Association, 13(3), 121-128.

Paglieri, F. (2015). Bogency and goodacies: On argument quality in virtue argumentation theory. Informal Logic, 35(1), 65-87.

Paul, R. (1993). Critical thinking, moral integrity and citizenship: Teaching for the intellectual virtues. In Critical thinking. How to prepare students for a rapidly changing world (pp. 255-268). Santa Rosa, CA: Foundation for Critical Thinking.

Schreier, M., \& Groeben, N. (1996). Ethical guidelines for the conduct in argumentative discussions: An exploratory study. Human Relations, 49(1), 123-132.

Schreier, M., Groeben, N., \& Christmann, U. (1995). That's not fair! Argumentational integrity as an ethics of argumentative communication. Argumentation, 9(2), 267-289.

Siegel, H. (1993). Not by skill alone: The centrality of character to critical thinking. Informal Logic, 15(3), 163-177.

Zagzebski, L. T. (1996). Virtues of the mind. New York: Cambridge University Press. 